\title{
Prevention Science Research With Children, Adolescents, and Families: Introduction
}

\author{
John C. Buckner, Ph.D., and Albert C. Cain, Ph.D.
}

$\mathrm{T}$ he concept of prevention has been of longstanding interest to mental health professionals. Over the years, the American Journal of Orthopsychiatry has published many noteworthy essays on prevention that have articulated its promise, its advances, and the challenges that lie ahead (Bower, 1963, 1987; Broskowski \& Baker, 1974; Deschin, 1968; Eisenberg, 1962; Garmezy, 1971; Runquist \& Behar, 1974). The Journal has also published many empirically based, prevention-oriented articles. In this issue, a special section is devoted to the topic of preventive intervention for children, adolescents, and families. The six articles it contains provide insight, both individually and as a set, into the current status of research in preventive intervention and illustrate many of the dominant themes and activities embodied in work at the cutting edge of the field.

Prevention-related activities have a relatively short history, while prevention as a concept has had a long past. As noted by Bower (1978), in Greek mythology, Asklepius, the God of medicine and healing, emphasized the early detection and treatment of illness carried out by skilled practitioners. Asklepius' daughter, Hygeia, had a somewhat different philosophy; her's emphasized the promotion of positive practices and competencies as a means of maintaining and improving one's overall health and mental health. While points of view about the merits of specific disease prevention versus health promotion still differ, many would argue that the two perspectives are complementary, and not competitive. They are surely not mutually exclusive.
Nevertheless, a lively debate continues between prevention advocates (Albee, 1982; Bloom, 1981; Eisenberg, 1962) and those who see such activities as premature, given the current state of knowledge, and as a drain on precious resources that could be better spent on treatment and research to help those with serious mental illnesses (Henderson, 1975; Lamb \& Zusman, 1979, 1981). The debate about prevention has touched on many professional spheres, including training of mental health professionals, organizational representation, social ethics, and issues of funding and reimbursement.

What was once a sizeable gap between the rhetoric and reality of mental health prevention research has been narrowing in recent years. Although prevention researchers have yet to develop interventions that can successfully reduce the incidence of such severe mental illnesses as schizophrenia and affective disorders, the area of "prevention science" has been quietly emerging within the field of mental health over the past decade, spearheaded by collaborative efforts at the National Institute of Mental Health (NIMH) (Coie, et al., 1993; NIMH, 1996, 1998; Reiss \& Price, 1996) and the Institute of Medicine (IOM) (IOM, 1994; Munoz, Mrazek, \& Haggerty, 1996).

As outlined by Kellam and Rebok (1992), Coie et al. (1993), and Beardslee in this issue, prevention science represents an amalgamation of knowledge, principles, and methods developed within the fields of epidemiology, human development, psychopathology, and education. Based on a sequence derived from public health

This special section was organized for the Journal by the authors, who are at: Department of Psychiatry, Harvard Medical School, Boston, MA (Buckner); and Department of Psychology, University of Michigan, Ann Arbor (Cain). 
principles, researchers following a prevention science approach build from prior studies that have identified risk or protective factors associated with disorders. As a first step, an investigator posits a coherent conceptual framework or theory regarding the etiology of a disorder based on previous retrospective or longitudinal studies. Typically, a "causal chain" of variables that lead to a disorder or targeted outcome is specified with a focus on identifying malleable risk and protective factors within this chain. The second stage is the design of a preventive intervention or trial to ameliorate one or more these risk factors or to enhance protective factors. An evaluation of the intervention is then conducted, usually under optimal circumstances (referred to as an "efficacy trial"), in order to test both the causal theory and the intervention's practical worth. Finally, if an intervention shows promise under ideal circumstances, communities may decide to adopt it: a test of such an intervention in broader, more real-world settings is called an "effectiveness" trial. In practice, of course, the actual sequence is not always so linear.

A prevention science approach imposes a combination of evaluation research with etiological or theory-building activities. The intent is to learn from both success and failure in order to improve subsequent interventions and refine etiological models. This involves more than determining the extent to which a preventive intervention effects a targeted outcome; it also addresses the question of how an intervention achieves its desired effect. To do so, it is necessary first to specify and then to measure one or more hypothesized mediating variables that may be influenced by the intervention and may, in turn, effect the outcome. In the language of prevention science, preventive intervention researchers specify "proximal" and "distal" targets that they attempt to modify. Proximal variables are hypothesized to mediate the impact of the intervention on the more distal outcome. If an intervention achieves its intended effect on the distal outcome, it is presumably through first having changed the proximal mediating variable. Alternatively, if an intervention fails to modify a targeted mediating variable appreciably, expectations of effects on later outcomes are lowered, although latent and "sleeper" effects may occur. Analytic steps for determining mediation have been outlined by James and Brett (1984), Baron and Kenny (1986), and, specifically for preventive trials, West and Aiken (1997).

In this special section, the paper by Heinicke and colleagues discusses an effort to examine mediation. In previous research, this group has demonstrated the beneficial effects of an intervention designed to improve mother-infant attachment and parenting practices among highrisk families (Heinicke, 1998). Here, a mediational model is proposed to explain how these effects were achieved. In keeping with the conceptual framework, the group examines whether the quality of support a mother receives from her partner mediates the intervention's impact on subsequent outcomes, namely attachment security and parenting behavior.

Similarly, Rotheram-Borus and colleagues propose a conceptual model for how their intervention might achieve its intended effects of reducing behavior that puts adolescents at risk of HIV and drug use. Their brief three-session intervention is designed to improve skills, knowledge, and attitudes (their hypothesized mediators or proximal outcomes) that they anticipate will, in turn, lead to reductions in such behavior (their more distal outcomes).

Abbott and colleagues report on an intervention at grade-school level designed, ultimately, to prevent adolescent crime and substance abuse by promoting academic achievement and bonding to school. They explore the extent to which the classroom-based intervention was implemented and whether it succeeded in changing their proximal outcomes of achievement and school bonding.

Preventive interventions can be classified into three subtypes, using definitions first proposed by Gordon (1983) and supported by the IOM (1994). These subtypes are universal, selective, and indicated. Universal interventions are aimed at a large group or population that has not been identified as being at high risk for a disease or disorder. Adding fluoride to a community's drinking water is an obvious public health example. In this issue, Spoth, and colleagues describe a universal intervention designed to promote family skills and enhance parent-child interactions in order to prevent substance use community-wide. Having previously reported positive effects of their intervention (Spoth, Redmond, \& Shin, 1998; Spoth, Redmond, \& Lepper, in press), they examine here whether the intervention had differential effects for particular subgroups: in this case, high-risk 
versus low-risk families, as defined by a cumulative risk factor count. This is an intrinsically important question to address, all the more so when it is advantageous to aim the intervention at those most likely to benefit, thereby improving the overall cost-benefit ratio.

Selective preventive interventions are aimed at individuals or subgroups of a population more likely to develop a disorder due to the presence of one or more risk factors. Both the HIV intervention described by Rotheram-Borus and colleagues and the mother-infant intervention described by Heinicke and colleagues are examples of selective preventive trials.

Finally, indicated preventive interventions are aimed at individuals who do not meet diagnostic criteria for a disorder but who evidence early manifestations or biological markers of the problem condition (Gordon, 1983). An alcohol abuse prevention program involving adolescents who have been caught drinking would be an example. In this issue, Beardslee describes a family-based clinician-led intervention designed to prevent depression among children in families with a parent who has recently suffered from major depression. This intervention could be considered selective in instances where the child evidences no signs of depression, or indicated for families in which the child, as well as the parent, reports depressive symptomatology.

Though private foundations have made splendid contributions to prevention activities, funding for prevention research typically comes from a federal agency with a specific mission to address a particular range or type of disorders (e.g., the NIMH for mental disorders, the National Institute on Drug Abuse for drug abuse and dependence disorders, the National Institute on Alcohol and Alcohol Abuse for alcohol abuse and dependence disorders). However, variables that have been identified as salient risk or protective factors in one arena typically do not honor bureaucratic boundaries. In this special section's lead article, Durlak examines a set of risk and protective factors that have been targeted across a range of different prevention programs in the fields of mental health, education, child welfare, alcohol and drug abuse, and physical health. His analysis indicates that intervening to modify specific risk and protective factors operating at each of the community, school, family, and individual levels of analysis can have effects across a wide array of psychosocial, educational, and health outcomes. As noted by the authors of the NIMH (1996) report, it is the responsibility of central funding agencies to work collaboratively with one another so as to facilitate preventive trials that target key risk factors likely to effect outcomes spanning multiple disciplines and programmatic borders.

As previously stated, a central starting point for prevention science is the prior identification of risk and protective factors for disorder. Considerable epidemiological investigation is still needed to further delineate these factors. This special section attempts to demonstrate the logical link between risk and protective factor studies and preventive interventions that attempt to refine theories of causal processes in real-world conditions, while simultaneously examining efficacy.

We have long since passed the point where preventive interventions can be justified only by appeals to social conscience, claims of inherent virtue, or cliches about a "bigger bang for the buck." Prevention science is narrowing the field's gap between rhetoric and reality through incremental advances in determining which types of interventions work, and for whom. This has been brought about, in part, by stronger links to theory, as well as by improvements in research methods and statistics. With such steps, prevention science, though still in its early stages, offers great promise in making the vital concept of prevention more tangible, attractive, and accessible.

\section{REFERENCES}

Albee, G.W. (1982). Preventing psychopathology and promoting human potential. American Psychologist, 37, 1043-1050.

Baron, R.M., \& Kenny, D.A. (1986). The moderatormediator variable distinction in social psychological research: Conceptual, strategic, and statistical considerations. Journal of Personality and Social Psychology, 51, 1173-1182.

Bloom, B.L. (1981). The logic and urgency of primary prevention. Hospital and Community Psychiatry, 32, 839-843.

Bower, E.M. (1963). Primary prevention of mental health and emotional disorders: A conceptual framework and action possibilities. American Journal of Orthopsychiatry, 33, 832-848.

Bower, E.M. (1987). Prevention: A word whose time has come. American Journal of Orthopsychiatry, $57,4-5$.

Broskowski, A., \& Baker, F. (1974). Professional, organizational, and social barriers to primary prevention. American Journal of Orthopsychiatry, 44, 707-719.

Coie, J.D., Watt, N.F., West, S.G., Hawkins, J.D., 
Asarnov, J.R., Markman, H.J., Ramey, S.L., Shure,. MG., \& Long, B. (1993). The science of prevention: A conceptual framework and some directions for a national research program. American Psychologist, 48, 1013-1022.

Deschin, C.S. (1968). The future direction of social work.1. From concem with problems to emphasis on prevention. American Journal of Orthopsychiatry, 38, 9-17.

Eisenberg, L. (1962). If not now, when? American Journal of Orthopsychiatry, 32, 781-793.

Garmezy, N. (1971). Vulnerability research and the issues of primary prevention. American Journal of Orthopsychiatry, 41, 101-116.

Gordon, R. (1983). An operational classification of disease prevention. Public Health Reports, 98, 107-109.

Heinicke, C.M., Fineman, N., Rodning, C., Ruth, G., Recchia, S., \& Guthrie, D. (1998). Relationshipbased intervention with at-risk mothers: Outcomes in first year of life. Manuscript submitted for publication.

Henderson, J. (1975). Object relations and a new social psychiatry: The illusion of primary prevention. Bulletin of the Menninger Clinic, 39, 233-245.

Institute of Medicine. (1994). Reducing risks for mental disorders: Frontiers for preventive intervention research. Washington, DC: National Academy Press.

James, L.R., \& Brett, J.M. (1984). Mediators, moderators, and tests for mediation. Journal of Applied Psychology, 69, 307-321.

Kellam, S.G., \& Rebok, G.W. (1992). Building developmental and etiologic theory through epidemiologically based preventive intervention trials. In J. McCord \& R.E. Tremblay (Eds.), Preventing antisocial behavior: Interventions from birth through adolescence (pp.162-195). New York: Guilford Press.

Lamb, H.R., \& Zusman, J. (1979). Primary prevention in perspective. American Journal of Psychiatry, 136, 12-17.

Lamb, H.R., \& Zusman, J. (1981). A new look at pri- mary prevention. Hospital and Community Psychiatry, 32, 843-848.

Munoz, R.R., Mrazek, P.J., \& Haggerty, R.J. (1996). Institute of Medicine report on prevention of mental disorders: Summary and commentary. American Psychologist, 51, 1116-1122.

National Institute of Mental Health. (1996). A plan for prevention research for the National Institute of Mental Health: A report to the National Advisory Mental Health Council (NIMH Publication \#96-4093). Rockville, MD: Author.

National Institute of Mental Health. (1998). Priorities for prevention research at NIMH: A report to the National Advisory Mental Health Council Workgroup on Mental Disorders Prevention Research (NIL Publication \#98-4321). Rockville, MD: Author.

Reiss, D., \& Price, R.H. (1996). National research agenda for prevention research: The National Institute of Mental Health Report. American Psychologist, 51, 1109-1115.

Runquist, M.P., \& Behar, L.B. (1974). Prevention of mental health problems: Meeting needs or imposing values? American Journal of Orthopsychiatry, 44, 269-270.

Spoth, R., Redmond, C., Shin, C. (1998). Direct and indirect latent variable parenting outcomes of two universal family-focused preventive interventions: Extending a public health-oriented research base. Journal of Consulting and Clinical Psychology, 66, 385-399.

Spoth, R., Redmond, C., \& Lepper, H. (in press). Alcohol initiation outcomes of universal familyfocused preventive interventions: One and two year follow-ups of a controlled study. Journal of Studies on Alcohol.

West, S.G., \& Aiken, L.S. (1997). Toward understanding individual effects in multicomponent prevention programs: Design and analysis strategies. In K.J. Bryant, M. Windle, \& S.G. West (Eds.), The science of prevention: Methodological advances from alcohol and substance abuse research (pp.167-209). Washington, DC: American Psychological Association. 